\title{
Effects of Nateglinide and Glibenclamide on Prothrombotic Factors in Naïve Type 2 Diabetic Patients Treated with Metformin: A 1-Year, Double-Blind, Randomized Clinical Trial
}

\author{
Giuseppe Derosa ${ }^{1}$, Angela D’Angelo ${ }^{1}$, Elena Fogari ${ }^{1}$, Sibilla Salvadeo ${ }^{1}$, \\ Alessia Gravina ${ }^{1}$, Ilaria Ferrari ${ }^{1}$ and Arrigo F.G. Cicero ${ }^{2}$
}

\begin{abstract}
Objective To evaluate the effect on coagulation and fibrinolysis parameters and on non-conventional cardiovascular risk factors of metformin plus nateglinide or glibenclamide in naïve type 2 diabetes patients.

Patients and Methods A total of 248 type 2 diabetic patients were enrolled and randomly assigned to receive nateglinide or glibenclamide, and metformin for 12 months. We assessed body mass index (BMI), glycated hemoglobin $\left(\mathrm{HbA}_{\mathrm{lc}}\right.$ ), fasting plasma glucose (FPG), postprandial plasma glucose (PPG), fasting plasma insulin (FPI), postprandial plasma insulin (PPI), homeostasis model assessment index (HOMA index), lipid profile with lipoprotein (a) [Lp(a)], fibrinogen (Fg), plasminogen activator inhibitor-1 (PAI-1), tissue plasminogen activator (t-PA), homocysteine (Hcy), systolic blood pressure (SBP), diastolic blood pressure (DBP).

Results After 9 months of treatment, both tested drug combinations were similarly associated with a significant reduction in FPG (nateglinide, $-17.2 \%$; glibenclamide, $-16.9 \%$, both $\mathrm{p}<0.05$ ) compared to the baseline, while $\mathrm{HbA}_{\mathrm{cc}}(-17.3 \%, \mathrm{p}<0.05)$ and PPG $(-15.2 \%, \mathrm{p}<0.05)$ significantly decreased only in the nateglinide group. After one year of treatment, compared to the baseline the nateglinide group showed a significant reduction in $\mathrm{HbA}_{\mathrm{lc}}(-21 \%, \mathrm{p}<0.01)$, FPG $(-20.7 \%), \mathrm{p}<0.01$, PPG $(-21.5 \%, \mathrm{p}<0.05)$, HOMA index $(-25.4 \%$, $\mathrm{p}<$ $0.05)$; the glibenclamide group, showed a significant reduction in $\mathrm{HbA}_{\mathrm{lc}}(-11 \%, \mathrm{p}<0.05)$, FPG $(-23.2 \%$, $\mathrm{p}<$ $0.05)$, PPG $(-11.2 \%, \mathrm{p}<0.05)$, and HOMA index $(-23.9 \%, \mathrm{p}<0.05)$ but to a minor extent. Moreover, the $\mathrm{HbA}_{\mathrm{lc}}$ difference value from baseline observed in the nateglinide-treated group was significantly higher than that observed in the glibenclamide group. Therefore the nateglinide-treated patients showed a significant reduction in some prothrombotic parameters (PAI- $1=-19 \%, \mathrm{Lp}(\mathrm{a})=-31 \%$, and $\mathrm{Hcy}=-32.3 \%$, all $\mathrm{p}<0.05$ ), whereas the glibenclamide-treated patients did not.

Conclusion Nateglinide appears to improve glycemic control as well as the levels of some prothrombotic parameters compared to glibenclamide when administered in combination with metformin.
\end{abstract}

Key words: nateglinide, glibenclamide, metformin, prothrombotic parameters

(DOI: 10.2169/internalmedicine.46.0320)

\section{Introduction}

It is well-known that diabetes changes the thrombohaemorrhagic balance which exists in healthy flowing blood. This change predisposes the diabetic patient to various thromboembolic conditions, leading to increased mortality and mor- bidity of these subjects (1). In different studies, type 2 diabetes appears to be an independent risk factor for thromboembolic stroke, independently of age (2), and a strong predictor of venous thromboembolism (3). Many hypotheses have been postulated to fully explain the prothrombotic condition of diabetic patients (4). A main actor could be the increased dietary glycemic load due to replacing fats with car-

${ }^{1}$ Department of Internal Medicine and Therapeutics, University of Pavia, Italy and "'G. Descovich" Atherosclerosis Study Center, "D. Campanacci” Clinical Medicine and Applied Biotechnology Department, University of Bologna, Italy

Received for publication May 17, 2007; Accepted for publication July 25, 2007

Correspondence to Dr. Giuseppe Derosa, giuseppe.derosa@unipv.it 
bohydrates or increasing intake of rapidly absorbed carbohydrates (ie, high glycemic index) that can create a selfperpetuating insulin resistance state and predicts greater thrombotic risk (5). In the context of insulin resistance, insulin has reduced effects on the phosphatidylinositol 3 kinase $(\mathrm{PI} 3 \mathrm{~K})$ pathway, whereas mitogen-activated protein kinase activity is maintained. The result is an exaggeration of the mitogenic actions of insulin leading to vascular smooth muscle proliferation and elevated plasminogen activator inhibitor (PAI)-1 (6), the major inhibitor of endogenous thrombolysis, thereby promoting thrombosis (7). Hyperhomocysteinemia, a consequence of disturbed methionine metabolism, appears also to be an independent risk factor for atherothrombotic events, even in diabetic subjects (8). Other factors are involved in the thrombofilic status associated to diabetes, like increased plasma level of XII, XI, and VIII coagulation factors (9), platelet hypersensitivity to collagen (10), an increased circulating pool of tissue factor (11), and sometimes also an increase in Lipoprotein (a) plasma level (12).

Some antihyperglycemic treatments have demonstrated to reduce blood hypercoagulability in diabetic patients (13). In particular, metformin, a biguanide, is able to decrease the plasma level of PAI-1 and clotting factor VII (14), also when associated to sulphanylureas (15) or thiazolidinediones (16). However, no data are available as it regards the combined effects of metformin associated with other classes of antihyperglycemic drugs such for instance d-phenylalanine derivatives on prothrombotic state. For this reason, the aim of our study is to evaluate the differential effect on coagulation and fibrinolysis parameters and on non conventional cardiovascular risk factors of the association between metformin plus nateglinide or glibenclamide in naïve type 2 diabetes patients.

\section{Methods}

\section{Study design}

This 12 month, multicenter, double-blind, randomized, controlled, parallel-group trial was conducted at the Department of Internal Medicine and Therapeutics, University of Pavia (Pavia, Italy); the "G. Descovich" Atherosclerosis Study Center, "D. Campanacci" Clinical Medicine and Applied Biotechnology Department, University of Bologna (Bologna, Italy); and in the Diabetes Care Unit at S. Carlo Hospital of Milano (Milano, Italy).

The study protocol was approved at each site by institutional review boards and was conducted in accordance with the 1994 Declaration of Helsinki and its amendments (17), and the Code of Good Clinical Practice.

\section{Patients}

Caucasian patients aged $\geq 18$ of either sex were eligible for inclusion in the study if they had: 1) type 2 diabetes mellitus according to the American Diabetes Association
(ADA) criteria (18) (duration, $\geq 6$ months), 2) poor glycemic control (glycosylated hemoglobin $\left[\mathrm{HbA}_{\mathrm{lc}}\right]$ level, >7.0\%), 3) hypertension according to the World Health Organization criteria (19) (systolic/diastolic blood pressure, $\geq 130 / \geq 85$ $\mathrm{mm} \mathrm{Hg}$ ) and 4) they were overweight (body mass index [BMI], 25.0-28.0 kg/m²) (20). A total of 233 (116 men and 117 women) subjects were included in this study. None of the selected subjects were taking hypolipidemic drugs, diuretics, $\beta$-blockers or thyroxin. Suitable patients, identified from a review of case notes and/or computerized clinic registers, were contacted by investigators in person or by telephone.

Patients were excluded if they had a history of ketoacidosis or had unstable or rapidly progressive diabetic retinopathy, nephropathy, or neuropathy; impaired hepatic function (defined as plasma aminotransferase and/or gamma-glutamyltransferase level higher than the upper limit of normal [ULN] for age and sex), impaired renal function (defined as serum creatinine level higher than the ULN for age and sex), or severe anemia. Patients with serious cardiovascular disease (CVD) (eg, New York Heart Association class I-IV congestive heart failure or a history of myocardial infarction or stroke) or cerebrovascular conditions within 6 months before study enrollment also were excluded. Women who were pregnant or breastfeeding or of childbearing potential and not taking adequate contraceptive precautions were also excluded. All patients provided written informed consent to participate.

\section{Treatment}

Patients were randomly assigned to receive nateglinide or glibenclamide after 6 months of run-in, in which patients were titrated to nateglinide (starting dose $180 \mathrm{mg} / \mathrm{day}$ ), glibenclamide (starting dose $7.5 \mathrm{mg} /$ day). Metformin (starting dose $1,500 \mathrm{mg} /$ day) was added in each arm independently of the glycemic control after 1 month of run-in (Fig. 1). The final doses were $300 \pm 60,12.5 \pm 2.5$, and $2,500 \pm$ $500 \mathrm{mg} /$ day, respectively.

Patients were randomized using envelopes containing randomization codes prepared by a statistician. A copy of the randomization code was provided only to the person responsible for performing the statistical analysis. The code was only broken after database lock, but could have been broken for individual patients in cases of emergency, such as hospitalization or suspicion of a serious adverse event.

Nateglinide, glibenclamide and metformin were supplied as identical, opaque, white capsules in coded bottles to ensure the double-blind status of the study. At baseline, we weighed participants and gave them a bottle containing a 100-day supply of study medication. Throughout the study, we instructed patients to take their first dose of new medication on the day after they were given the study medication. A bottle containing the study medication for the next treatment period was given to participants at the 3-month visit. At the same time, all unused medication was retrieved for inventory. All medications were provided free of charge. 


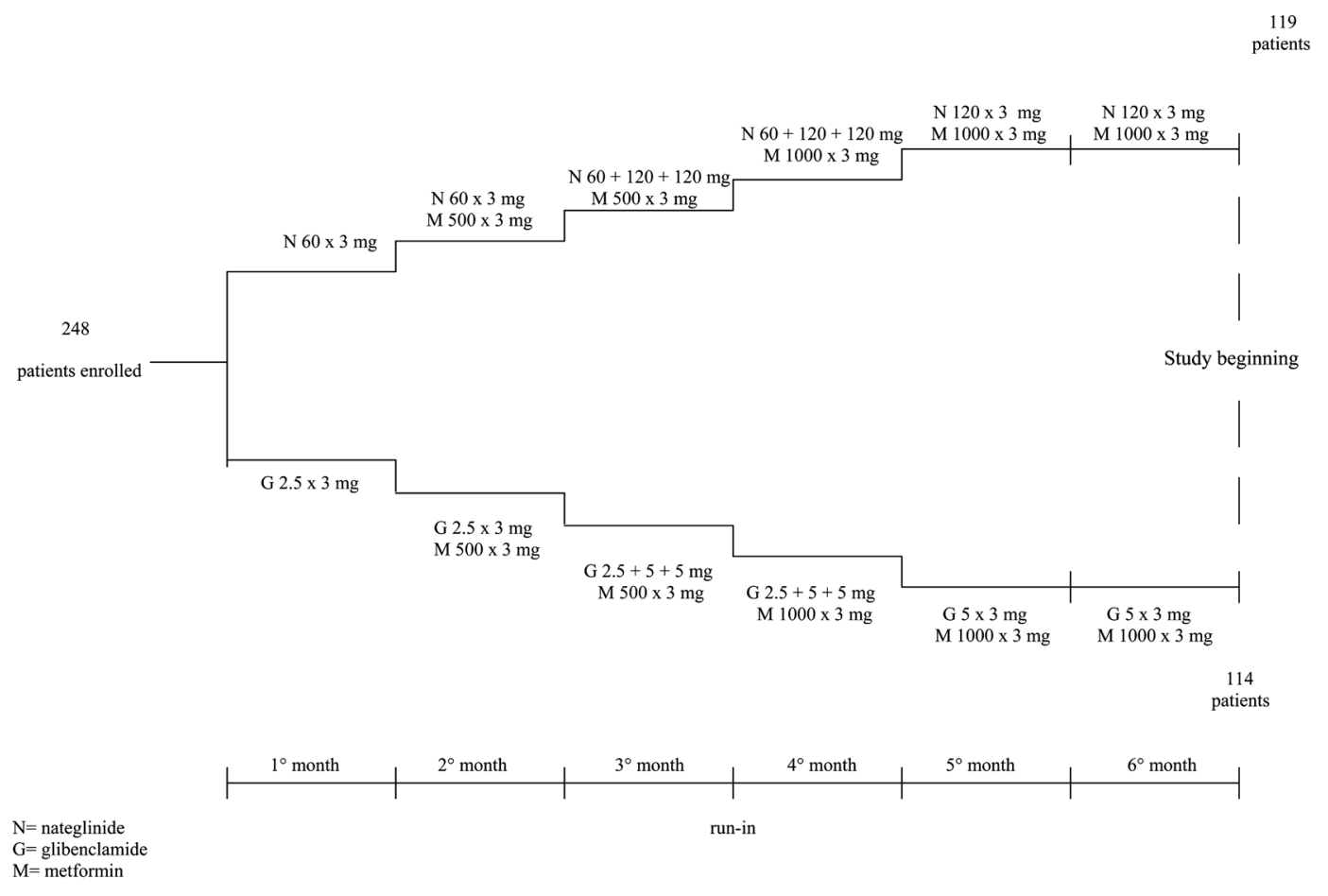

Figure 1. Scheme of the study

\section{Diet and exercise}

At baseline, patients began a controlled-energy diet ( 600 kcal daily deficit), based on ADA recommendations (21), that contained $50 \%$ of calories from carbohydrates, $30 \%$ from fat $(6 \%$ saturated), and $20 \%$ from proteins, with a maximum cholesterol content of $300 \mathrm{mg} / \mathrm{d}$, and $35 \mathrm{~g} / \mathrm{d}$ of fiber. Each center's standard diet advice was given by a dietitian and/or specialist physician. Every two weeks dietitians and/or specialists provided instruction on dietary intakerecording procedures as part of a behavior-modification program and then from month one they used the patients' food diaries for counseling. During the study, behavior-modification sessions on weight-loss strategies were given to individual patients at baseline, one at 6 months, and four with all patients at 3, 6, 9, and 12 months. Individuals were also encouraged to increase their physical activity by walking briskly or riding a stationary bicycle for 20 to $30 \mathrm{~min}, 3$ to 5 times per week. The recommended changes in physical activity throughout the study were not assessed.

\section{Efficacy, tolerability, and compliance assessments}

Before starting the study, all patients underwent an initial screening assessment that included a medical history; physical examination; vital signs; a 12-lead electrocardiogram; measurements of height and body weight; calculation of BMI; assessment of glycemic control $\left(\mathrm{HbA}_{\mathrm{lc}}\right.$, fasting and postprandial plasma glucose, fasting and postprandial plasma insulin levels [FPG, PPG, FPI, and PPI, respectively], homeostasis model assessment [HOMA] index), and lipid profile [total cholesterol (TC), low density lipoprotein-cholesterol (LDL-C), high density lipoprotein-cholesterol (HDL-
C), triglycerides ( $\mathrm{Tg}$ ), ], lipoprotein(a) $\mathrm{Lp}(\mathrm{a})$, fibrinogen $(\mathrm{Fg})$, plasminogen activator inhibitor 1 (PAI-1), tissue-plasminogen activator (t-PA), homocysteine (Hcy), systolic blood pressure (SBP), and diastolic blood pressure (DBP). Body Mass Index, $\mathrm{HbA}_{\mathrm{Ic}}$, FPG, PPG, FPI, PPI, HOMA index, TC, LDL-C, HDL-C, Tg, Lp(a), Fg, PAI-1, tP-A, Hcy, SBP, and DBP values were also assessed at 3, 6, 9, and 12 months.

All plasmatic variables were determined after a 12 hour overnight fast, except PPG and PPI, which were determined 2 hours after lunch. Venous blood samples were drawn by a research nurse for all patients between 8:00 AM and 9:00 AM. We used plasma obtained by addition of $\mathrm{Na}_{2}$-EDTA, 1 $\mathrm{mg} / \mathrm{mL}$, and centrifuged at $3,000 \mathrm{~g}$ for $15 \mathrm{~min}$ at $4^{\circ} \mathrm{C}$. Immediately after centrifugation, the plasma samples were frozen and stored at $-80^{\circ} \mathrm{C}$ for $\leq 3$ months. All measurements were performed in a central laboratory and the biologist responsible for the laboratory performed the assays.

BMI was calculated by the investigators as weight in kilograms divided by the square of height in meters. The estimate of insulin resistance was calculated using the HOMA index, with the following formula:

Insulin resistance $=$ FPI $(\mu \mathrm{U} / \mathrm{mL}) \times F P G(\mathrm{mmol} / \mathrm{L}) / 22.5$, as described by Matthews et al (22) (Normal if $<2.5$, marker of insulin-resistance if $\geq 2.5$ ).

Blood pressure (BP) measurements were obtained from each patient (using the right arm) in the seated position, using a standard mercury sphygmomanometer (Erkameter 3000, ERKA, Bad Tolz, Germany) (Korotkoff I and V) with a cuff of appropriate size. BP was measured by the same investigator at each visit, in the morning before daily drug intake and after the patient had rested for $\geq 10 \mathrm{~min}$ in a quiet room. Three successive BP readings were obtained at 1- 


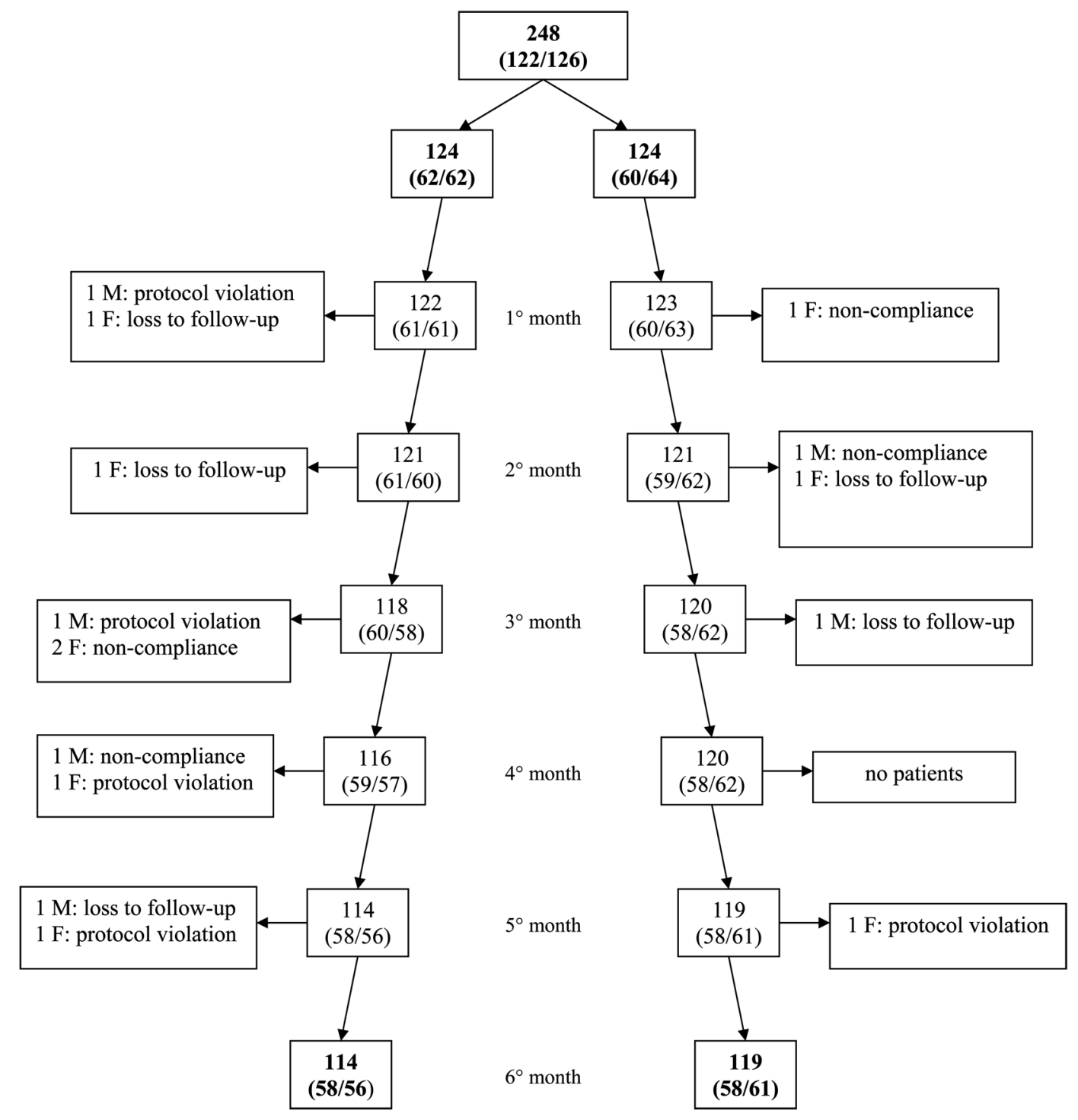

Figure 2. Flowchart of the patients (males/females) showing the withdrawals during the study; G or $\mathrm{G}+\mathrm{M}$ on the left, $\mathrm{N}$ or $\mathrm{N}+\mathrm{M}$ on the right.

minute intervals, and the mean of the 3 readings was calculated.

$\mathrm{HbA}_{1 \mathrm{c}}$ level was measured using high-performance liquid chromatography (DIAMAT, Bio-Rad Laboratories, Inc., Hercules, California; normal value, 4.2\%-6.2\%), with intra- and interassay coefficients of variation (CsV) of $<2 \%$ (23). Plasma glucose was assayed using a glucose-oxidase method (GOD/PAP, Roche Diagnostics, Mannheim, Germany) with intra- and interassay $\mathrm{CsV}<2 \%$ (24). Plasma insulin was assayed with Phadiaseph Insulin Radioimmunoassay (Pharmacia, Uppsala, Sweden) using a second antibody to separate the free and antibody-bound 125 I-insulin (intra- and interassay $\mathrm{CsV}, 4.6 \%$ and $7.3 \%$, respectively) (25).

Total cholesterol and $\mathrm{Tg}$ levels were determined using fully enzymatic techniques $(26,27)$ on a clinical chemistry analyzer (HITACHI 737; Hitachi, Tokyo, Japan); intra- and interassay $\mathrm{CsV}$ were $1.0 \%$ and $2.1 \%$ for TC measurement, and $0.9 \%$ and $2.4 \%$ for $\mathrm{Tg}$ measurement, respectively. HDL$\mathrm{C}$ level was measured after precipitation of plasma apo Bcontaining lipoproteins with phosphotungstic acid (28) intra- and interassay $\mathrm{CsV}$ were $1.0 \%$ and $1.9 \%$, respectively; LDL-C level was calculated by the Friedewald formula (29). Apo A-I and Apo B were measured by immuno-turbidimetric assays (Boehringer-Mannheim, Mannheim, Germany); the inter- and intrassay $\mathrm{CsV}$ were 3-5\%, respectively $(30,31)$.

Plasminogen activator inhibitor 1 was assayed with a commercial two-stage indirect enzymatic assay (Spectrolyse, Biopool AB, Umea, Sweden) and intra- and inter-assay CVs were $5.9 \%$ (32). Fibrinogen was determined according to Clauss. The intra-assay coefficient of variation for the $\mathrm{Fg}$ method was $<5 \%$ (33). Tissue-plasminogen activator was measured by a commercially available ELISA kit (Spectrolyse, Biopool AB) and intra- and inter-assay CVs were $7.0 \%$ and $10.4 \%$, respectively (34). Lipoprotein (a) was measured by a sandwich enzyme-linked immunosorbent assay (ELISA) method, that is insensitive to the presence of plasminogen, using the commercial kit Macra-Lp(a) (SDI, Newark, Delaware, USA) $(35,36)$; the intra- and inter-assay $\mathrm{CsV}$ of this method were $5 \%$ and $9 \%$, respectively. Homo- 
cysteine was measured by a modified procedure of Araki and Sako (37) with high pressure liquid chromatography and fluorescence detection. The intra-assay variation of the method was $2.5 \%$.

Treatment tolerability was assessed at each study visit using an accurate interview of patients by the investigators, and comparisons of clinical and laboratory values with baseline levels. Medication compliance was assessed by the investigators by counting the number of pills returned at the time of specified clinic visits.

\section{Statistical analysis}

An intention-to-treat (ITT) analysis was conducted in patients who had received $\geq 1$ dose of study medication and had a subsequent efficacy observation. Patients were included in the tolerability analysis if they had received $\geq 1$ dose of trial medication after randomization and had undergone a subsequent tolerability observation. The null hypothesis that the expected mean $\mathrm{HbA}_{\mathrm{ic}}$, FPG, PPG, HOMA index change from baseline to 12 months of double-blind treatment did not differ significantly between nateglinide and glibenclamide treatments was tested using analysis of variance and analysis of covariance (ANCOVA) models (38). Similar analyses were applied to Lp(a), Fg, PAI-1, tPA, and Hcy. The statistical significance of the independent effects of treatments on the other variables was determined using ANCOVA. A 1-sample $t$ test was used to compare values obtained before and after treatment administration; 2sample $t$ tests were used for between-group comparisons. The Bonferroni correction for multiple comparisons also was carried out. Statistical analysis of data was performed using the Statistical Package for Social Sciences software version 11.0 (SPSS Inc., Chicago, Illinois). Data are presented as mean (SD). For all statistical analyses, $\mathrm{p}<0.05$ was considered statistically significant.

\section{Results}

\section{Study sample}

A total of 248 patients (124 men and 124 women) were enrolled in the trial. One hundred twenty-four (60 men and 64 women) $(50.0 \%)$ were randomized to double-blind treatment with nateglinide and 124 (62 men and 62 women) $(50.0 \%)$ with glibenclamide. Two hundred thirty-three patients $(94.0 \%)$ completed the study (119 patients in the nateglinide arm, 58 men and 61 women, and 114 patients in the glibenclamide arm, 58 men and 56 women).

A total of 15 patients $(6.0 \%)$ (6 men and 9 women) did not complete the study; the reasons for premature withdrawal included protocol violation, loss to follow-up, noncompliance. The characteristics of the patient population at study entry, shown in Tables 1,2 , were similar in the two treatment groups.

\section{Efficacy}

\section{Body mass index}

No BMI change was observed after 3, 6, 9, and 12 months in both groups. Results are reported in detail in Tables 1,2 .

\section{Blood pressure}

No SBP or DBP change was obtained in the two groups after 3, 6, 9, and 12 months (Tables 1, 2).

\section{Glycemic control}

No $\mathrm{HbA}_{1 \mathrm{c}}$ change was observed after 3 , and 6 months in nateglinide group, while a significant $\mathrm{HbA}_{1 \mathrm{c}}$ decrease was obtained after $9(\mathrm{p}<0.05)$, and $12(\mathrm{p}<0.01)$ months in nateglinide group compared to the baseline value and this change was significant after $12(\mathrm{p}<0.05)$ months respect to glibenclamide group. No significant $\mathrm{HbA}_{1 \mathrm{c}}$ variation was present at 3,6 , and 9 months in glibenclamide group while significant $\mathrm{HbA}_{\mathrm{lc}}$ decrease was obtained after $12(\mathrm{p}<0.05)$ months in this group compared to the baseline value (Table 2). No significant FPG change was present at 3 and 6 months in both groups. After 9 and 12 months, mean FPG levels were significantly decreased in both groups $(\mathrm{p}<0.05$ and $\mathrm{p}<0.01$, respectively) (Tables 1,2 ) compared to baseline. Postprandial glucose did not show any significant change after 3 , and 6 months in nateglinide group, and after 3, 6 and 9 months in glibenclamide group. Significant PPG decrease was obtained only at 9 months $(\mathrm{p}<0.05)$ in nateglinide group, and after 12 months in glibenclamide and nateglinide group $(\mathrm{p}<0.05$ and $\mathrm{p}<0.01$, respectively) respect to baseline (Tables 1,2 ). Fasting plasma insulin and PPI did not show any significant change after 3, 6, 9, and 12 months in both groups compared to the baseline value. Furthermore, HOMA index decrease was obtained only at 12 months $(\mathrm{p}<0.05)$ compared to the baseline value in both groups.

\section{Lipid profile and lipoprotein variables}

No TC, LDL-C, HDL-C, and Tg change was obtained during the study in both groups (Tables 1, 2).

\section{Coagulation and fibrinolysis parameters}

No PAI-1 change was observed in any group after 3, 6, and 9 months. Significant reductions in PAI-1 $(\mathrm{p}<0.05)$ were seen after 12 months in nateglinide group compared to the baseline value and this change was significant $(\mathrm{p}<0.05)$ compared to glibenclamide group. No PAI-1 variation was present after 12 months in glibenclamide group compared to the baseline value (Fig. 3). No significant change in Fg and t-PA was seen during the study in each group (Table 1).

\section{Non conventional cardiovascular risk factors}

No significant Lp(a), and Hcy change was obtained after 3, 6, and 9 months in both groups. Significant $\operatorname{Lp}(\mathrm{a})$, and 
Table 1. Baseline Characteristics and Parameter Changes at $3^{\circ}, 6^{\circ}, 9^{\circ}$, and $12^{\circ}$ Month of the Study in Nateglinide Group

\begin{tabular}{|c|c|c|c|c|c|}
\hline & \multicolumn{5}{|c|}{ Nateglinide + Metformin } \\
\hline & Baseline & 3 months & 6 months & 9 months & 12 months \\
\hline $\mathrm{n}$ & 119 & - & - & - & - \\
\hline $\operatorname{sex}(M / F)$ & $58 / 61$ & - & - & - & - \\
\hline age (years) & $55 \pm 5$ & - & - & - & - \\
\hline Diab. Dur. (years) & $5 \pm 2$ & - & - & - & - \\
\hline $\operatorname{BMI}\left(\mathrm{Kg} / \mathrm{m}^{2}\right)$ & $26.4 \pm 1.4$ & $26.2 \pm 1.2$ & $26.6 \pm 1.3$ & $26.5 \pm 1.3$ & $26.8 \pm 1.6$ \\
\hline $\mathrm{HbA}_{1 \mathrm{c}}(\%)$ & $8.1 \pm 1.0$ & $7.3 \pm 0.8$ & $7.1 \pm 0.7$ & $6.7 \pm 0.5^{\circ}$ & $6.4 \pm 0.4^{\cdots \wedge}$ \\
\hline $\mathrm{FPG}(\mathrm{mg} / \mathrm{dl})$ & $174 \pm 21$ & $165 \pm 20$ & $156 \pm 19$ & $144 \pm 18^{\circ}$ & $138 \pm 17^{*}$ \\
\hline PPG (mg/dl) & $191 \pm 28$ & $184 \pm 25$ & $176 \pm 24$ & $162 \pm 22^{\circ}$ & $150 \pm 21^{*}$ \\
\hline FPI $(\mu \mathrm{U} / \mathrm{ml})$ & $26.6 \pm 4.8$ & $26.1 \pm 4.6$ & $26.3 \pm 4.6$ & $25.9 \pm 4.4$ & $24.7 \pm 4.2$ \\
\hline PPI $(\mu \mathrm{U} / \mathrm{ml})$ & $68.2 \pm 9.3$ & $67.5 \pm 9.1$ & $66.4 \pm 8.9$ & $67.3 \pm 9.0$ & $65.3 \pm 8.7$ \\
\hline HOMA index & $11.4 \pm 4.8$ & $11.1 \pm 4.6$ & $10.5 \pm 4.3$ & $9.8 \pm 4.0$ & $8.5 \pm 3.9^{\circ}$ \\
\hline $\mathrm{TC}(\mathrm{mg} / \mathrm{dl})$ & $196 \pm 18$ & $192 \pm 17$ & $190 \pm 16$ & $186 \pm 15$ & $181 \pm 14$ \\
\hline LDL-C (mg/dl) & $121 \pm 13$ & $120 \pm 13$ & $118 \pm 12$ & $115 \pm 12$ & $113 \pm 11$ \\
\hline HDL-C (mg/dl) & $42 \pm 5$ & $42 \pm 5$ & $44 \pm 8$ & $45 \pm 7$ & $43 \pm 6$ \\
\hline $\mathrm{Tg}(\mathrm{mg} / \mathrm{dl})$ & $156 \pm 40$ & $150 \pm 37$ & $146 \pm 36$ & $142 \pm 34$ & $141 \pm 33$ \\
\hline $\mathrm{Lp}(\mathrm{a})(\mathrm{mg} / \mathrm{dl})$ & $29.3 \pm 18.9$ & $27.4 \pm 17.5$ & $25.7 \pm 17.2$ & $22.2 \pm 16.5$ & $20.1 \pm 14.2^{\circ}$ \\
\hline $\mathrm{Fg}(\mathrm{mg} / \mathrm{dl})$ & $341 \pm 42$ & $338 \pm 40$ & $344 \pm 45$ & $331 \pm 41$ & $326 \pm 40$ \\
\hline PAI-1 (ng/ml) & $44.5 \pm 15.9$ & $42.6 \pm 15.4$ & $40.1 \pm 15.0$ & $37.9 \pm 14.2$ & $36.1 \pm 13.1^{\bullet}$ \\
\hline $\mathrm{t}-\mathrm{PA}(\mathrm{ng} / \mathrm{ml})$ & $26.2 \pm 9.1$ & $26.4 \pm 9.1$ & $25.3 \pm 8.6$ & $24.1 \pm 8.0$ & $23.2 \pm 7.6$ \\
\hline Hcy $(\mu \mathrm{mol} / 1)$ & $13.6 \pm 2.4$ & $12.9 \pm 2.2$ & $11.6 \pm 2.1$ & $10.1 \pm 2.0$ & $9.2 \pm 1.8^{\curvearrowleft \wedge}$ \\
\hline $\mathrm{SBP}(\mathrm{mmHg})$ & $136.8 \pm 4.4$ & $136.1 \pm 4.2$ & $135.3 \pm 4.0$ & $136.1 \pm 3.9$ & $134.5 \pm 3.6$ \\
\hline DBP $(\mathrm{mmHg})$ & $87.3 \pm 3.8$ & $86.8 \pm 3.7$ & $86.1 \pm 3.5$ & $85.8 \pm 3.5$ & $85.4 \pm 3.4$ \\
\hline
\end{tabular}

\footnotetext{
Data are means $\pm \mathrm{SD} ;{ }^{\bullet} \mathrm{p}<0.05$ vs baseline; ${ }^{*} \mathrm{p}<0.01$ vs baseline; ${ }^{\wedge} \mathrm{p}<0.05$ vs glibenclamide + metformin.

BMI: body mass index; $\mathrm{HbA}_{1 \mathrm{c}}$ : glycated haemoglobin; FPG: fasting plasma glucose; PPG: postprandial plasma glucose; FPI: fasting plasma insulin; PPI: postprandial plasma insulin; HOMA index: homeostasis model assessment index; TC: total cholesterol; LDL-C: low density lipoproteincholesterol; HDL-C: high density lipoprotein-cholesterol; Tg: triglycerides; Lp(a): Lipoprotein (a); Fg: Fibrinogen; PAI-1: Plasminogen Activator Inhibitor-1; t-PA: tissue Plasminogen Activator; Hcy: Homocysteine; SBP: systolic blood pressure; DBP: diastolic blood pressure
}

Hcy decrease $(\mathrm{p}<0.05)$ was observed after 12 months in nateglinide group compared to baseline values and this change was significant $(\mathrm{p}<0.05)$ compared to glibenclamide group. No $\mathrm{Lp}(\mathrm{a})$, and Hcy variation was present after 12 months in glibenclamide group (Table 1, Figs. 4 and 5).

\section{Discussion}

Metformin is a biguanide and its main mechanism of action is to counteract peripheral insulin-resistance (39). It is the only antihyperglycemic drug that has shown relevant positive effects on hard clinical outcomes: it prevented approximately the $40 \%$ of vascular events in a large retrospective study carried out on more than 12,000 patients (40) and it significantly reduced any diabetes-related endpoint in the United Kingdom Prospective Diabetes Study (41). However, type 2 diabetes mellitus is a progressive disorder, and although oral monotherapy is often initially successful, it is associated with a high secondary failure rate, which contributes to the development of long-term diabetes complications resulting from persistent hyperglycemia (42). For patients not taking insulin, accumulating evidence suggests that combination therapy using oral antidiabetic agents with different mechanisms of action may be effective in achieving and maintaining target blood glucose levels (43).

Glibenclamide is a well-known first generation sulphanylurea (SU). As all SUs, it binds a specific site on the adenosine triphosphate (ATP)-sensitive potassium channels of the SU receptor, subsequently opening calcium channels and thus triggering insulin exocytosis from the pancreatic beta cell (44).

Nateglinide, a D-phenylalanine derivative lacking either a SU or benzamido moiety, stimulates insulin release via closure of (ATP)-sensitive potassium channels in pancreatic beta-cell, a primary mechanism of action it shares with glibenclamide and other SUs (45). Nateglinide binds rapidly to the SU SUR1 receptor with a relatively low affinity, and it dissociates from it extremely rapidly in a manner of seconds (46). Thus, nateglinide has a rapid onset and short duration of action stimulating insulin secretion in vivo and providing good control of postprandial hyperglycemia when taken immediately prior to meals, thus restoring the normal 
Table 2. Baseline Characteristics and Parameter Changes at $3^{\circ}, 6^{\circ}, 9^{\circ}$, and $12^{\circ}$ Month of the Study in Glibenclamide Group

\begin{tabular}{|c|c|c|c|c|c|}
\hline & \multicolumn{5}{|c|}{ Glibenclamide + Metformin } \\
\hline & Baseline & 3 months & 6 months & 9 months & 12 months \\
\hline$n$ & 114 & - & - & - & - \\
\hline $\operatorname{sex}(M / F)$ & $58 / 56$ & - & - & - & - \\
\hline age (years) & $56 \pm 4$ & - & - & - & - \\
\hline Diab. Dur. (years) & $4 \pm 2$ & - & - & - & - \\
\hline $\mathrm{BMI}\left(\mathrm{Kg} / \mathrm{m}^{2}\right)$ & $26.5 \pm 1.5$ & $26.5 \pm 1.5$ & $26.7 \pm 1.6$ & $26.8 \pm 1.7$ & $26.9 \pm 1.7$ \\
\hline $\mathrm{HbA}_{1 \mathrm{c}}(\%)$ & $8.2 \pm 1.1$ & $7.9 \pm 0.8$ & $7.7 \pm 0.8$ & $7.6 \pm 0.7$ & $7.3 \pm 0.6^{\circ}$ \\
\hline $\mathrm{FPG}(\mathrm{mg} / \mathrm{dl})$ & $177 \pm 24$ & $168 \pm 21$ & $160 \pm 18$ & $147 \pm 17^{\circ}$ & $136 \pm 15^{\circ}$ \\
\hline PPG (mg/dl) & $187 \pm 24$ & $182 \pm 23$ & $174 \pm 22$ & $169 \pm 21$ & $166 \pm 20^{\circ}$ \\
\hline FPI $(\mu \mathrm{U} / \mathrm{ml})$ & $27.1 \pm 5.0$ & $26.9 \pm 4.8$ & $26.5 \pm 4.7$ & $26.8 \pm 4.7$ & $25.7 \pm 4.4$ \\
\hline PPI $(\mu \mathrm{U} / \mathrm{ml})$ & $67.0 \pm 9.2$ & $66.8 \pm 9.0$ & $66.2 \pm 8.8$ & $66.0 \pm 8.7$ & $65.5 \pm 8.6$ \\
\hline HOMA index & $11.7 \pm 4.9$ & $11.2 \pm 4.8$ & $10.6 \pm 4.6$ & $9.7 \pm 4.5$ & $8.9 \pm 4.1^{\circ}$ \\
\hline TC (mg/dl) & $193 \pm 17$ & $189 \pm 17$ & $188 \pm 16$ & $186 \pm 16$ & $185 \pm 15$ \\
\hline LDL-C (mg/dl) & $119 \pm 12$ & $115 \pm 12$ & $110 \pm 11$ & $108 \pm 10$ & $104 \pm 10$ \\
\hline HDL-C (mg/dl) & $42 \pm 5$ & $40 \pm 4$ & $41 \pm 5$ & $42 \pm 5$ & $41 \pm 4$ \\
\hline $\operatorname{Tg}(\mathrm{mg} / \mathrm{dl})$ & $161 \pm 42$ & $157 \pm 40$ & $151 \pm 37$ & $145 \pm 33$ & $140 \pm 31$ \\
\hline $\mathrm{Lp}(\mathrm{a})(\mathrm{mg} / \mathrm{dl})$ & $28.5 \pm 17.4$ & $29.1 \pm 17.8$ & $28.6 \pm 17.5$ & $27.2 \pm 17.1$ & $26.7 \pm 16.9$ \\
\hline $\mathrm{Fg}(\mathrm{mg} / \mathrm{dl})$ & $352 \pm 45$ & $340 \pm 43$ & $329 \pm 41$ & $320 \pm 40$ & $314 \pm 39$ \\
\hline PAI-1 (ng/ml) & $43.9 \pm 16.2$ & $43.5 \pm 16.0$ & $43.2 \pm 15.8$ & $41.8 \pm 15.7$ & $41.3 \pm 15.6$ \\
\hline $\mathrm{t}-\mathrm{PA}(\mathrm{ng} / \mathrm{ml})$ & $27.5 \pm 10.0$ & $27.1 \pm 9.6$ & $26.6 \pm 9.1$ & $25.7 \pm 8.9$ & $24.6 \pm 8.9$ \\
\hline Hcy $(\mu \mathrm{mol} / 1)$ & $13.9 \pm 2.6$ & $13.6 \pm 2.5$ & $13.1 \pm 2.4$ & $12.9 \pm 2.3$ & $12.7 \pm 2.2$ \\
\hline $\mathrm{SBP}(\mathrm{mmHg})$ & $137.4 \pm 4.6$ & $136.8 \pm 4.5$ & $136.2 \pm 4.3$ & $135.7 \pm 4.0$ & $135.4 \pm 3.8$ \\
\hline $\mathrm{DBP}(\mathrm{mmHg})$ & $88.1 \pm 3.5$ & $88.8 \pm 3.7$ & $88.3 \pm 3.6$ & $87.5 \pm 3.5$ & $86.8 \pm 3.5$ \\
\hline
\end{tabular}

Data are means $\pm \mathrm{SD} ;{ }^{\bullet} \mathrm{p}<0.05$ vs baseline; $\ddot{p}<<0.01$ vs baseline

BMI: body mass index; $\mathrm{HbA}_{1 \mathrm{c}}$ : glycated haemoglobin; FPG: fasting plasma glucose; PPG: postprandial plasma glucose; FPI: fasting plasma insulin; PPI: postprandial plasma insulin; HOMA index: homeostasis model assessment index; TC: total cholesterol; LDL-C: low density lipoproteincholesterol; HDL-C: high density lipoprotein-cholesterol; Tg: triglycerides; Lp(a): Lipoprotein (a); Fg: Fibrinogen; PAI-1: Plasminogen Activator Inhibitor-1; t-PA: tissue Plasminogen Activator; Hcy: Homocysteine; SBP: systolic blood pressure; DBP: diastolic blood pressure.

physiological first and early phase of insulin secretion (47). The association of nateglinide and metformin has already been proven to be an efficacious and safe antidiabetic strategy in type 2 diabetic patients (48). Its efficacy has been tested also as a first line-therapy in treatment-naïve patients with recently developed type 2 diabetes: the PRESERVEbeta trial compared the effect of the nateglinide-metformin association to the glibenclamide-metformin one on the longterm metabolic control of 428 newly diagnosed type 2 diabetics: both protocols appeared to be efficacious in obtaining a good glucose homeostasis, but the nateglinide-metformin treated group experienced significantly less episodes of hypoglycemia ( $8.8 \%$ vs $17.7 \%$ ) (49). Glibenclamide-metformin association has also been proven as an efficacious and safe therapeutic approach for type 2 diabetes mellitus (50).

In a previous report, Barnett et al compared the acute metabolic effect of nateglinide and glibenclamide with a cross-over study. They demonstrated that nateglinide significantly improves early prandial measures of insulin and glucose response to a standard meal when compared to glibenclamide (51). In the present study, after 9 months of treatment, both tested drug combinations were similarly associ- ated to a significant reduction in FPG (nateglinide, 17.2\%; glibenclamide, $16.9 \%$ ) compared to the baseline, while $\mathrm{HbA}_{\mathrm{lc}}(-17.3 \%)$ and PPG $(-15.2 \%)$ were significantly decreased only in the nateglinide group. After one year of treatment, compared to the baseline the nateglinide group showed a significant reduction in $\mathrm{HbA}_{\mathrm{lc}}(-21 \%)$, FPG $(-20.7 \%)$, PPG (-21.5\%), HOMA index (-25.4\%); the glibenclamide group, showed a significant reduction in $\mathrm{HbA}_{\mathrm{lc}}(-11 \%)$, FPG (-23.2\%), PPG (-11.2\%), and HOMA index $(-23.9 \%)$ but to a minor extent. The effects of nateglinide and glibenclamide on insulin-resistance parameters are in agreement with previous reports $(52,53)$, and may be related to the most relevant effect of netaglinide on postprandial glycaemia rise. In contrast to what was previously reported by other authors $(52,53)$, the $\mathrm{HbA}_{1 \mathrm{c}}$ decrease observed in the nateglinide treated group was significantly higher than that observed with glibenclamide. This was possibly related to the relatively higher mean dosage of nateglinide (300 mg/day) administered to our patients in comparison to the previously cited studies.

What is more specific in our study is the observation that the nateglinide-treated patients showed a significant reduc- 


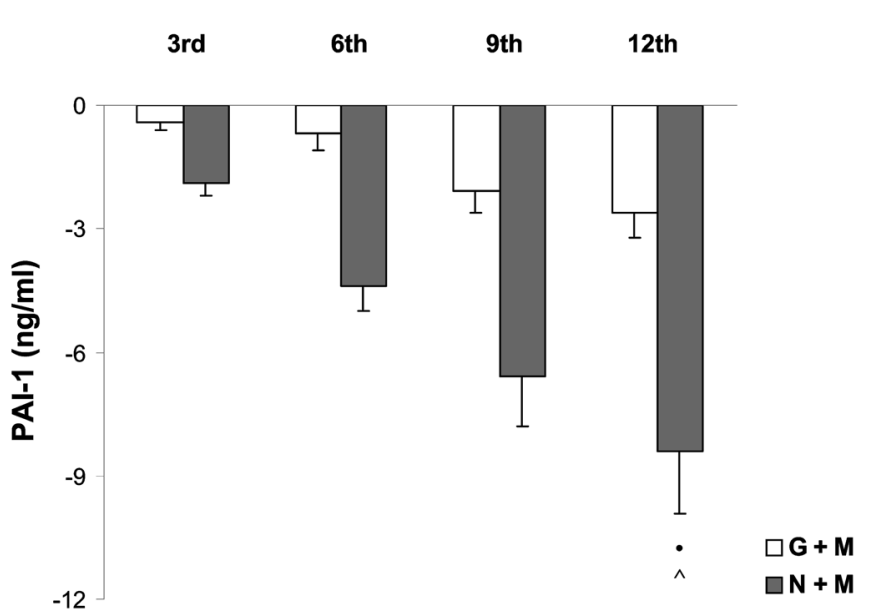

Values are mean \pm SD

$\bullet \mathbf{p}<0.05$, change from baseline; ${ }^{\wedge} \mathbf{p}<0.05$ between treatments. PAI-1: plasminogen activator inhibitor-1.

Figure 3. Change in PAI-1 from baseline to that at 3, 6, 9, and 12 months in patients receiving Glibenclamide or Nateglinide.

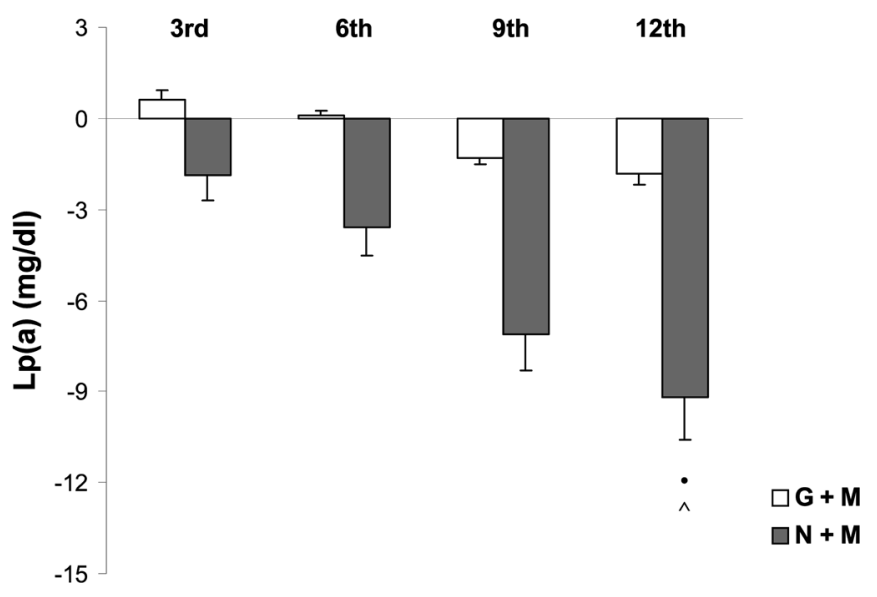

Values are mean \pm SD

$\bullet p<0.05$, change from baseline; ${ }^{\wedge} p<0.05$ between treatments. Lp(a): lipoprotein(a).

Figure 4. Change in $\operatorname{Lp}(\mathbf{a})$ from baseline to that at 3, 6, 9, and 12 months in patients receiving Glibenclamide or Nateglinide.

tion in some prothrombotic parameters (PAI-1=-19\%, $\mathrm{Lp}(\mathrm{a})=-31 \%$, and Hcy=-32.3\%), whereas glibenclamide treated patients did not. We already observed similar results

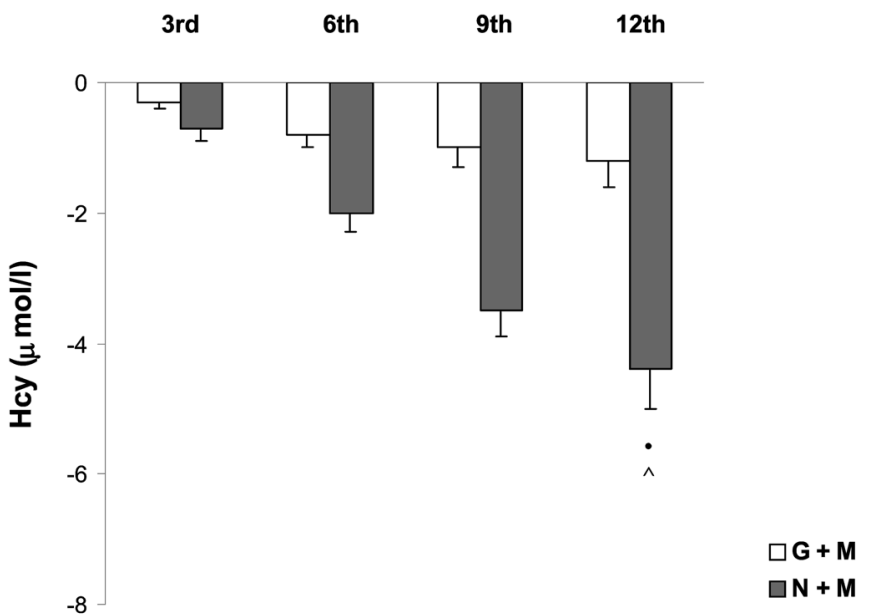

Values are mean \pm SD

$\bullet p<0.05$, change from baseline; ${ }^{\wedge} \mathbf{p}<0.05$ between treatments. Hcy: homocysteine.

Figure 5. Change in Hcy from baseline to that at 3, 6, 9, and 12 months in patients receiving Glibenclamide or Nateglinide.

in a previous study carried out with another D-phenylalanine derivative, repaglinide (54). Tentolouris et al recently shown that nateglinide significantly improves fibrinolytic parameters such as PAI-1 and tPA (55). To the best of our knowledge no previous study has specifically investigated the effect of nateglinide on Lp(a) and Hcy. Our hypothesis is that this positive effect could be related to the nateglinide improving effect on post-prandial glucose metabolism that is more early than that observed under glibenclamide treatment. On the other hand, a previous study showed that the normalization of post-prandial glycaemia by insulin administration is not associated with an improvement in PAI-1 and Hcy plasma level in type 2 diabetes subjects (56). Further studies are needed to evaluate if glibenclamide could be also associated to similar improvement in a longer follow-up and to understand the molecular mechanism of the nategliniderelated improvement in prothrombotic parameters.

Based on the present study, carried out on a relatively small sample of selected patients, type 2 diabetes naïve patients, nateglinide appears to improve glycemic control and the plasma level of some prothrombotic parameters better than glibenclamide when administered in combination with metformin.

\section{References}

1. Biondi-Zoccai GG, Abbate A, Liuzzo G, Biasucci LM. Atherothrombosis, inflammation, and diabetes. J Am Coll Cardiol 41: 1071-1077, 2003.

2. Abbott RD, Curb JD, Rodriguez BL, et al. Age-related changes in risk factor effects on the incidence of thromboembolic and hemorrhagic stroke. J Clin Epidemiol 56: 479-486, 2003.

3. Tsai AW, Cushman M, Rosamond WD, Heckbert SR, Polak JF, Folsom AR. Cardiovascular risk factors and venous thromboem- bolism incidence: the longitudinal investigation of thromboembolism etiology. Arch Intern Med 162: 1182-1189, 2002.

4. Theuma P, Fonseca VA. Inflammation and emerging risk factors in diabetes mellitus and atherosclerosis. Curr Diab Rep 3: 248-254, 2003.

5. Liu S, Willett WC. Dietary glycemic load and atherothrombotic risk. Curr Atheroscler Rep 4: 454-461, 2002.

6. Reusch JE. Current concepts in insulin resistance, type 2 diabetes 
mellitus, and the metabolic syndrome. Am J Cardiol 90: 19G-26G, 2002.

7. Tsikouris JP, Suarez JA, Meyerrose GE. Plasminogen activator inhibitor-1: physiologic role, regulation, and the influence of common pharmacologic agents. J Clin Pharmacol 42: 1187-1199, 2002.

8. Herrmann W, Knapp JP. Hyperhomocysteinemia: a new risk factor for degenerative diseases. Clin Lab 48: 471-481, 2002.

9. Ghosh K. Thrombohaemorrhagic balance in diabetes mellitus. J Indian Med Assoc 100: 428-433, 2002.

10. Calverley DC, Hacker MR, Loda KA, et al. Increased platelet Fc receptor expression as a potential contributing cause of platelet hypersensitivity to collagen in diabetes mellitus. $\mathrm{Br} \mathrm{J}$ Haematol 121: 139-142, 2003.

11. Sambola A, Osende J, Hathcock J, et al. Role of risk factors in the modulation of tissue factor activity and blood thrombogenicity. Circulation 107: 973-977, 2003.

12. Saely CH, Koch L, Schmid F, et al. Lipoprotein(a), type 2 diabetes and vascular risk in coronary patients. Eur J Clin Invest 36: 91-97, 2006.

13. Derosa G, Cicero AFG, Gaddi A, et al. A comparison of the effects of Pioglitazone and Rosiglitazone combined with Glimepiride on prothrombotic state in patients with the metabolic syndrome. Diab Res Clin Pract 69: 5-13, 2005.

14. Grant P. Beneficial effects of metformin on haemostasis and vascular function in man. Diabetes Metab 4: 44-52, 2003.

15. Derosa G, Gaddi A, Piccinni MN, et al. Antithrombotic effects of combination rosiglitazone-metformin vs. combination glimepiridemetformin therapy in patients with type 2 diabetes and metabolic syndrome. Pharmacotherapy 25: 637-645, 2005.

16. Derosa G, D'Angelo A, Ragonesi PD, et al. Effects of rosiglitazone and pioglitazone combined with metformin on the prothrombotic state of patients with type 2 diabetes mellitus and metabolic syndrome. J Int Med Res 34: 545-555, 2006.

17. Proposed International Guidelines for Biomedical Research Involving Human Subjects. The Council for International Organisation of Medical Sciences. Geneva, 1982.

18. American Diabetes Association. Screening for diabetes (Position Statement). Diabetes Care 24: S21-S24, 2001.

19. 1999 World Health Organization-International Society of Hypertension Guidelines for the Management of Hypertension. Guidelines Subcommittee. J Hypertens 17: 151-183, 1999.

20. World Health Organization: Obesity: Preventing and Managing the Global Epidemic. Report of WHO Consultation on Obesity. WHO, Geneva, June 1997.

21. American Diabetes Association. Nutrition recommendations and principles for people with diabetes mellitus (Position Statement). Diabetes Care 24: S44-S47, 2001.

22. Matthews DR, Hosker JP, Rudenski AS, Naylor BA, Treacher DF, Turner RC. Homeostasis model assessment: Insulin resistance and beta-cell function from fasting plasma glucose and insulin concentrations in man. Diabetologia 28: 412-419, 1985.

23. Bunn HF, Gabbay HK, Gallop PM. The glycosylation of haemoglobin. Relevance to diabetes mellitus. Science 200: 21-27, 1978.

24. European Diabetes Policy Group. A desktop guide to type 2 diabetes mellitus. Diab Med 16: 716-730, 1999.

25. Heding LG. Determination of total serum insulin (IRI) in insulintreated diabetic patients. Diabetologia 8: 260-266, 1972.

26. Klose S, Borner K. Enzymatische Bestimmung des Gesamtcholesterins mit dem Greiner Selective Analyzer (GSA II). J Clin Chem Clin Biochem 15: 121-130, 1978.

27. Wahlefeld AW. Triglycerides determination after enzymatic hydrolysis. In: Methods of Enzymatic Analysis. 2nd English ed. Bermeyer HU, Ed. Academic Press, Inc, New York, 1974: 18-31.

28. Havel RJ, Edr HA, Bragdon JH. The distribution and chemical composition of ultracentrifugally separated lipoproteins in human serum. J Clin Invest 34: 1345-1353, 1955.

29. Friedewald WT, Levy RI, Fredrickson DS. Estimation of the concentration of low density lipoprotein in plasma, without use of the preparative ultracentrifuge. Clin Chem 18: 499-502, 1972.

30. Leblond L, Marcel YL. The amphipathic a-helical repeats of apolipoprotein A-I are responsible for binding of high density lipoproteins to HepG2 cells. J Biol Chem 266: 6058-6067, 1991.

31. De Loof H, Rosseneu M, Yang CY, Li WH, Gotto AM Jr, Chan L. Human apolipoprotein: analysis of internal repeats and homology with other apolipoproteins. J Lip Res 28: 1455-1465, 1987.

32. Juhan-Vague I, Collen D. On the role of coagulation and fibrinolysis in atherosclerosis. Ann Epidemiol 2: 427-438, 1992.

33. Clauss A. Gerinnungsphysiologische Schnellmethode zur Bestimmung des Fibrinogens. Acta Haematol 17: 237-246, 1959.

34. Narayanan S. Preanalytical aspects of coagulation testing. Haematologica 80: 1-6, 1995.

35. Scanu AM, Scandian L. Lipoprotein (a): structure, biology and clinical relevance. Adv Intern Med 36: 249-270, 1991.

36. Uterman G, Weber W. Protein composition of lipoprotein(a). J Clin Invest 80: 458-465, 1987.

37. Araki A, Sako Y. Determination of free and total homocysteine in human plasma by high performance chromatography with fluorescence detection. J Chromatography 422: 43-52, 1987.

38. Winer BJ. Statistical Principles in Experimental Design. 2nd ed. McGraw-Hill, New York, 1971.

39. Vague $P$. Is metformin more than an oral hypoglycaemic agent? Diabet Metab 29: 5-7, 2003.

40. Johnson JA, Simpson SH, Majumdar SR, Toth EL. Decreased mortality associated with the use of metformin compared with sulphanylurea monotherapy in type 2 diabetes. Diabetes Care 25: 2244-2248, 2002.

41. UK Prospective Diabetes Study (UKPDS) Group. Effect of intensive blood-glucose control with metformin on complications in overweight patients with type 2 diabetes. Lancet 253: 854-865, 1998.

42. American Diabetes Association. American Diabetes Association: clinical practice recommendations 2002. Diabetes Care 25: S1147, 2002.

43. Van Gaal LF, De Leeuw IH. Rationale and options for combination therapy in the treatment of Type 2 diabetes. Diabetologia 46 : 44-50, 2003.

44. Proks P, Reimann F, Green N, Gribble F, Ashcroft F. Sulfonylurea stimulation of insulin secretion. Diabetes 51: S368-S376, 2002.

45. Hu S, Wang S, Dunning BE. Glucose-dependent and glucosesensitizing insulinotropic effect of nateglinide: comparison to sulfonylureas and repaglinide. Int J Exp Diabetes Res 2: 63-72, 2001.

46. Norman P, Rabasseda X. Nateglinide: A structurally novel, shortacting, hypoglycemic agent. Drugs Today 37: 411-426, 2001.

47. Ball AJ, Flatt PR, McClenaghan NH. Acute and long-term effects of nateglinide on insulin secretory pathways. Br J Pharmacol 142: 367-373, 2004.

48. Marre M, Van Gaal L, Usadel KH, Ball M, Whatmough I, Guitard C. Nateglinide improves glycaemic control when added to metformin monotherapy: results of a randomized trial with type 2 diabetes patients. Diabetes Obes Metab 4: 177-186, 2002.

49. Gerich J, Raskin P, Jean-Louis L, Purkayastha D, Baron MA. PRESERVE-beta: two-year efficacy and safety of initial combination therapy with nateglinide or glyburide plus metformin. Diabetes Care 28: 2093-2099, 2005.

50. Tosi F, Muggeo M, Brun E, et al. Combination treatment with metformin and glibenclamide versus single-drug therapies in type 2 diabetes mellitus: a randomized, double-blind, comparative study. Metabolism 52: 862-867, 2003.

51. Barnett AH, Anderson DM, Shelley S, Morgan R, Owens DR. A placebo-controlled crossover study comparing the effects of nateg- 
DOI: $10.2169 /$ internalmedicine.46.0320

linide and glibenclamide on postprandial hyperglycaemia and hyperinsulinaemia in patients with type 2 diabetes. Diabetes Obes Metab 6: 104-113, 2004.

52. Fonseca VA, Kelley DE, Cefalu W, et al. Hypoglycemic potential of nateglinide versus glyburide in patients with type 2 diabetes mellitus. Metabolism 53: 1331-1335, 2004.

53. Shiba T. Improvement of insulin resistance by a new insulin secretagogue, nateglinide-analysis based on the homeostasis model. Diabetes Res Clin Pract 62: 87-94, 2003.

54. Derosa G, Mugellini A, Ciccarelli L, Crescenzi G, Fogari R. Comparison between repaglinide and glimepiride in patients with type 2 diabetes mellitus: a one-year, randomized, double-blind assess- ment of metabolic parameters and cardiovascular risk factors. Clin Ther 25: 472-484, 2003.

55. Tentolouris N, Boutati E, Karambakalis N, et al. Acute nateglinide administration in subjects with type 2 diabetes: effects on postprandial metabolism, coagulation, and fibrinolysis. Nutr Metab Cardiovasc Dis 15: 6-12, 2005.

56. Gallagher A, Home PD. The effect of improved post-prandial blood glucose control on post-prandial metabolism and markers of vascular risk in people with Type 2 diabetes. Diabetes Res Clin Pract 67: 196-203, 2005.

(C) 2007 The Japanese Society of Internal Medicine http://www.naika.or.jp/imindex.html 